University of Nebraska - Lincoln

DigitalCommons@University of Nebraska - Lincoln

$1-1-2005$

\title{
Broadening Middle-School Students' Images of Science and Scientists
}

Diandra Leslie-Pelecky

University of Nebraska -- Lincoln, diandra2@unl.edu

Gayle A. Buck

University of Nebraska-Lincoln, gabuck@indiana.edu

Angela Zabawa

Lincoln Public Schools, Lincoln NE

Follow this and additional works at: https://digitalcommons.unl.edu/physicslesliepelecky

Part of the Physics Commons

Leslie-Pelecky, Diandra; Buck, Gayle A.; and Zabawa, Angela, "Broadening Middle-School Students' Images of Science and Scientists" (2005). Diandra Leslie-Pelecky Publications. 3.

https://digitalcommons.unl.edu/physicslesliepelecky/3

This Article is brought to you for free and open access by the Research Papers in Physics and Astronomy at DigitalCommons@University of Nebraska - Lincoln. It has been accepted for inclusion in Diandra Leslie-Pelecky Publications by an authorized administrator of DigitalCommons@University of Nebraska - Lincoln. 


\title{
Broadening Middle-School Students' Images of Science and Scientists
}

\author{
Diandra L. Leslie-Pelecky ${ }^{1}$, Gayle A. Buck, ${ }^{2}$ and Angela Zabawa ${ }^{3}$ \\ ${ }^{1}$ Department of Physics \& Astronomy and Center for Materials Research \& Analysis, University \\ of Nebraska - Lincoln, Lincoln NE 68588-0111, U.S.A. \\ ${ }^{2}$ Department of Teaching, Learning and Teacher Education, University of Nebraska - Lincoln, \\ Lincoln NE 68588-0355, U.S.A. \\ ${ }^{3}$ Lincoln Public Schools, Lincoln NE 68510, U.S.A.
}

\begin{abstract}
The 'mad scientist' stereotype is alive and well - and not an image most K-12 students can (or want to) embrace. Project Fulcrum, a National Science Foundation-funded GK-12 program, partners math, science and engineering graduate students with elementary and middle-level teachers. One project goal - broadening student images of science and scientists -is addressed by projects developed by the teacher/scientist teams that are focused on the specific needs of their students. The projects developed focus on scientists, the use of science in different types of jobs, and developing scientific skills. Pre-project research, in which teachers probe the motivation behind their students' attitudes, is a critical component of developing a successful project. Although determining the specific impact of this project on student attitudes is complicated by its being part of a larger project, teachers and scientists report enhanced awareness of student attitudes and the reasons underlying those attitudes, and generated ideas to address those motivations.
\end{abstract}

\section{INTRODUCTION}

The common stereotype of the nerdy white male described by Mead and Mertraux has not changed significantly since their 1957 paper. They describe a high-school student's perception of a scientist: “...a man who wears a white coat and works in a laboratory...is elderly or middle aged and wears glasses... wears a beard...is surrounded by equipment...[and] spends his days doing experiments" [1]. The prevalence of this stereotypical image is an asset and a liability to the scientific community [2]. While most people express respect and admiration for scientists [3], the dominant stereotype discourages those who do not fit the stereotype from seeing themselves as scientists. $[4,5]$ Children's attitudes toward science and their participation in science are strongly defined, highly gendered and formed as early as kindergarten $[2,6,7]$. These attitudes affect future education and career choices, as well as attitudes toward, for example, public support of scientific research $[8,9]$. The National Science Education Standards urge teachers to ensure that students develop a realistic picture of "women and men of various social and ethic backgrounds...with diverse interests, talents, qualities and motivations... engaging in the activities of science, engineering and related fields such as the health professions". They further suggest that students should learn about the skills necessary for science: communication ability, reasoning, insight, energy, creativity, intellectual honesty, tolerance of ambiguity, skepticism and openness to new ideas [10].

One often-proposed component to address these goals is involving research scientists and engineers in K-12 schools [11, 12]. The National Science Foundation's Graduate Teaching Fellows in K-12 Schools (GK-12) program encourages partnerships of graduate and 
undergraduate students with K-12 teachers. Project Fulcrum, the University of Nebraska Lincoln's GK-12 program, pairs Lead Teachers at elementary or middle-level schools with graduate students who are in residence at the school for the entire school year.

One of Project Fulcrum's goals is investigating how scientists can help broaden student images of science and scientists. Our previous research showed that student perceptions of science and scientists were highly gendered and significantly dependent on the personality and gender of the particular scientist [13]. One common result of 'scientist-in-the-classroom' projects is that students change their image of a scientist from the 'mad scientist' stereotype to a second image, which is that of the scientist who has spent the year in their classroom [14]. Although this may be a more realistic image, it fails to capture the diversity of people, interests and skills involved in science. In response to this problem, teachers and their graduate-student scientists developed a targeted project with the express focus of broadening student images of science and scientists. Lead teachers took primary responsibility for designing and documenting the project, which was counted as part of their GK-12 duties. Graduate-student scientists identified people and resources to help meet project goals. Activities from the past three years of projects are reported here.

\section{PRE-PROJECT RESEARCH}

An important emphasis was customizing each project to the needs of that school's students. The 'Image of Science and Scientists' survey [15] administered as part of overall project evaluation asks about students' perceptions of scientists including: where they work, what they do in their jobs, how they spend their free time, and if they have families and/or hobbies. The survey also asks whether students are interested in becoming a scientist. Pre-survey results by gender, science grade, and race/ethnicity were made available to the teachers; however, teachers were asked to do their own research to gain additional insight into the needs of their particular students. Individual teachers addressed several topics covered by the quantitative survey, but the open-ended nature of the teachers' questions allowed them to probe the reasons behind student answers. Examples of specific questions asked by teachers include: "What are important characteristics for being a scientist?", "What do scientists do?", "Where do scientists work?", and "Would you want to be a scientist? Why or Why not?".

All of the teachers reported that their pre-project research showed that students had overall positive images of scientists: they thought scientists were determined, courageous, persistent, smart, hardworking, dedicated, patient, organized, intelligent, observant, and curious; however, the majority of students viewed scientists as old men researching, using or mixing chemicals, or studying objects in a lab. When asked to describe where scientists work, one student responded, "a cold, dark lab". The teachers' research helped them plan projects to address specific issues.

\section{PROJECTS}

Gathering data prior to planning the project was critical. In most cases, teachers and graduate-student scientists were surprised by the students' reasoning. Student responses were the primary rationale used in designing each project. Secondary factors included the socioeconomic context of the school, scheduling and curricular foci. A teacher from a school with a diverse student population wanted her students to, "see themselves reflected as scientists, so they could see some possibilities for their futures". Another teacher at a school where most 
students likely would attend college chose to expose students to the breadth of possible math and science careers and the preparation necessary for each. The projects developed can be divided into three categories: a) scientists, b) people who use science in their jobs, and c) scientific skills.

\section{$\underline{\text { Scientists }}$}

Projects focused on learning about scientists can be classified into three subtypes: scientists visiting the classroom, student research on scientists, and a combination of student research and scientist visits. The first type of project, bringing scientists into the classroom, was popular and involved a number of faculty, graduate students and community scientists who had not been involved with Project Fulcrum before. Some teachers connected the visiting scientists to the curricular unit being studied. Some projects spread out scientist visits over a quarter, while others brought in multiple scientists on a single day. One project randomly paired scientists and non-scientists, and asked students to determine - first without any information other than just looking at the visitors - which of the visitors were scientists and why. Students then interviewed the visitors and revised their answers.

The second type of project required students to research scientists from different ethnic backgrounds, areas of science, ages, and genders using Internet and print resources. In some cases, students chose scientists of interest to them, while scientists were randomly assigned in other projects. Students presented their results using posters, making 'trading cards' and by writing 'Scientist Books'. A few projects combined Internet or print research of scientists with classroom visits. Students could interact personally with a scientist and their previous research allowed them to formulate the questions they wanted to ask prior to the scientists' visits.

\section{People who use science in their jobs}

Some teachers chose to focus on how science is used in careers that include, but are not limited to, those traditionally associated with 'science'. One project challenged students to find jobs that did not use science. Students created a table with science jobs in one column and jobs without science in the other column. Sharing tables resulted in heated debates between students about whether a certain job required science or a science skill. Another project had students identify and interview someone close to them (teacher, parent, relative, etc.) about their thoughts on science, and how they use science in their job. The students then compared the traits and skills of their role model with those of a scientist they had researched. Students at another school researched how people use the scientific method in different types of jobs.

\section{Using and building science skills}

The final type of project focused on scientific skills rather than scientists per se. The driving force for these projects was to motivate and assist students in developing their own science skills. One project focused on developing student questioning skills and began by having the students learn about how scientists use questions. Before meeting the scientists, students discussed what constitutes a good question and practiced asking their own questions. Visiting scientists discussed the driving questions in their research field and the specific question they are researching. Another project investigated how scientists solve problems, and compared this to problem solving in the students' lives. Focusing on how scientists use science skills and their 
applicability to seemingly non-science situations broadened students' view of scientists while providing them with real-life applications for what they were learning.

\section{ASSESSMENT}

Formative assessment techniques were discussed during some of the weekly group meetings the teachers attend as part of Project Fulcrum. Teachers received advice from project organizers and each other, and most projects evolved significantly as student feedback was gathered. At the project conclusion, teachers assessed students' attitudes and images of scientists formally and informally using student comments, surveys, journal questions, and/or poster projects. The majority of teachers noted comments made by their students during and after the project in their journals, while a few teachers administered formal surveys. Some surveys posed questions similar to those asked prior to starting the project, while others asked questions that arose during analysis of the project. Regardless of the project type, teachers used their summative assessments to link the idea of science and/or scientists to the students' lives. In one assessment, students were asked to make Venn diagrams comparing their skills with the skills of scientists. In another project, the teacher asked students to identify which one of their classmates they thought would be a good scientist and why. One group of students prepared poster presentations comparing and contrasting their personal role model with a scientist they had researched.

\section{DISCUSSION}

\section{Impact on students}

Teachers generally reported that their students' views of what scientists do and the specific fields in which they work broadened. For example, students identified more scientific fields (and specific careers) after the project than before. The list of places a scientist might work broadened from "a lab" to include more diverse settings. Teachers reported the project assisted them in "helping their students think differently about science and scientists". Despite the focused project, teachers felt that having a graduate-student scientist interacting with the students on a regular basis was the biggest component in changing students' perceptions of scientists. Weekly contact enabled students and scientists to form personal relationships through which students learned about scientists' research, interests, families, and lives. Exposure to multiple scientists via visits or research, however, helped to broaden student perceptions.

\section{Impact on teachers}

Teachers overall felt that the project was worth the time spent, although the need to balance nature of science activities with those emphasized by standardized tests remains a concern and a challenge. Researching the needs of their specific students prior to planning a project proved to be a critical element. Although most of the teachers could predict student answers to the questions they asked, they often were surprised at the reasons given by the students for selecting those answers. Teachers were encouraged to use formative assessment and became more comfortable changing their projects in response to student reactions. The effect of the preproject research and formative assessment is becoming evident in other project components. 
Teachers have improved their ability to be flexible and recognize that changing a project should always be an option.

The project managers noted a change in the level of goals expressed by teachers participating for a second (or third) year. There was a clear evolution from exposing children to a diverse group of scientists to determining how they can use the project to help their students develop their own scientific skills. These projects are clearly goal driven and significantly shape how participating scientists interact with the students.

\section{Impact on scientists}

This type of project is ideal for involving graduate student and faculty scientists, as limited time commitment and preparation are required; however, it is beneficial to provide information about the goals of the project to classroom visitors prior to their visits. This project originally was called a 'role model project'; however, some graduate-student scientists expressed discomfort being designated a 'role model'. Scientists were uncertain as to how much they should 'sell' being a scientist. For example, a student question about how many hours a week they worked raised concern that the true answer would be discouraging to the students. Scientists were, however, happy to help dispel some of the stereotypes expressed by students, such as showing that not all scientists like Star Trek, or that some scientists do wear pink. A number of graduate-student scientists noted the prevalence of television and film personalities in student discussions of scientists and that this re-emphasized to them the importance of their participation in the K-12 classroom

\section{EVALUATION}

Evaluating the effectiveness of this project is difficult, in part due to its being one part of the GK-12 program as a whole, and in part due to other efforts with a similar focus, such as an $8^{\text {th }}$ grade unit requiring students to research scientists from underrepresented groups. From the three years of data gathered, the following elements are identified as critical for successful projects.

Scheduling. Teacher schedules are extremely full. One teacher linked his project with a human biology unit and the visiting scientists reinforced the curricular focus. Others spent a single, focused day on the project. Since each classroom is different, the teacher needs the flexibility to decide when and how to implement the project.

Research. Gathering student input - especially from open-ended response questions - prior to planning and during execution of the project is critical. Teachers' research shaped the projects, and continuing assessment ensured that they were meeting the needs of their students. One teacher, who planned a series of 8 speakers, got halfway through the project when her students became frustrated, stating "we've got it already - any person can be a scientist." This provided a great opportunity for the teachers to discuss when and how to change a project, and how to determine whether your students are telling you what they know you want to hear. A number of innovative summative assessments were developed during these conversations.

Support. Projects were discussed periodically during weekly teacher meetings. Teachers needed encouragement to change their projects in response to student input, as they tended to equate changing plans with poor initial planning. Teachers needed to be reminded not to compare their projects with each other because each classroom had different needs and thus 
different types of projects. The idea of not having a project template was challenging for the teachers, but was critical for ensuring that projects were focused on specific student needs.

\section{CONCLUSIONS}

While having a scientist in the classroom on a regular basis is important, a program specifically focused on broadening student attitudes about science and scientists prevents students from replacing one stereotype with another, albeit more appealing, stereotype. Research by teachers prior to planning the project, evaluation throughout the project, and support from project management are essential components for successful activities.

\section{ACKNOWLEDGEMENTS}

This project was supported by the National Science Foundation GK-12 program under DGE-0086358. We thank scientists supported by the NSF through Materials Research Science and Engineering Center grant DMR-0213808 for their participation and Vicki L. Plano Clark for comments on this manuscript.

\section{REFERENCES}

1. M. Mead and R. Metraux, Science 126 (1957) 384-390.

2. D. Chambers, Sci. Ed. 67 (1983) 255-265.

3. National Science Board, Science and Engineering Indicators. (National Science Foundation, 2002).

4. J. B. Kahle and J. Meece, "Research on Gender Issues in the Classroom", Handbook of Research on Science Teaching and Learning, ed. D. Gabel, (Macmillan, 1994) pp 542-557.

5. B. W.-L. Packard, E. D. Wong, paper presented at the Annual Meeting of the American Educational Research Association (Montreal, Canada, April 19-23, 1999).

6. T. Andre, M. Whigham, A. Hendrickson, S. Chambers, J. Res. Sci. Teach. 36 (1999) 719.

7. B. C. Bruce, S. P. Bruce, R. L. Conrad, H. J. Huang, J. Res. Sci. Teach 34 (1997) 69.

8. W. R. Snelling, R. F. Boruch, Science in Liberal Arts Colleges. A Longitudinal Study of 49 Selective Colleges (Columbia University Press, 1972).

9. E. R. Hall, P. Post-Kammer, Career Development Quarterly 35 (1987) 206.

10. National Research Council, National Science Education Standards, (National Academy Press, 1996).

11. N. Lane, American Scientist 84 (1996) 208.

12. B. M. Alberts, “A 10-Step Recipe for Starting a Partnership Program”, Science Education Partnerships: Manual for Scientists and K-12 Teachers, ed. A. Sussman (University of California at San Francisco, 1993) pp 15-18.

13. G. A. Buck, D. L. Leslie-Pelecky, S. R. Kirby, J. Elem. Sci. Ed. 14 (2003) 1.

14. S. P. Bruce, B. C. Bruce, Comput. Hum. Behav. 16 (2000) 241.

15. J. Krajkovich, J. Smith, J. Res. Sci. Teach. 19 (1982) 39. 